This is the peer reviewed version of the following article:

Rodriguez-Moreno, S., Panadero, S., \& Vázquez, J. J. (2020). Risk of mental ill-health among homeless women in Madrid (Spain). Archives of Women's Mental Health, 23, 657-664,

which has been published in final form at:

https://doi.org/10.1007/s00737-020-01036-w

This article may be used for non-commercial purposes in accordance with Springer Terms and Conditions for Use of Self-Archived Versions. 
Accepted version of the article:

Rodriguez-Moreno, S., Panadero, S., \& Vázquez, J. J. (2020). Risk of mental ill-health among homeless women in Madrid (Spain). Archives of Women's Mental Health, 23, 657-664. https://doi.org/10.1007/s00737-020-01036-w

Copyright: Springer.

\section{RISK OF MENTAL ILL-HEALTH AMONG HOMELESS WOMEN IN MADRID (SPAIN)}

Sara Rodriguez-Moreno ${ }^{1}$, Sonia Panadero ${ }^{1}$ and José Juan Vázquez ${ }^{2}$

1. Clinical Psychology Department, School of Psychology, Complutense University of Madrid, 28223, Madrid, Spain.

2. Social Psychology Department. Alcala University, 28801, Alcala de Henares. Madrid, Spain.

Corresponding author: Sara Rodriguez-Moreno, Clinical Psychology Department, Psychology School, Complutense University of Madrid, 28223, Madrid, Spain. Email: sarairod@ucm.es

Acknowledgments Sara Rodriguez-Moreno is a $\mathrm{PhD}$ candidate at Complutense University of Madrid and this work will be part of her PhD work on mental health and psychological treatments in homeless women. The authors want to thank all women experiencing homelessness for their generosity to participate in the study.

Funding statement: This research was supported by the "Agencia Estatal de Investigación" of the "Ministerio de Economía, Industria y Competitividad" of Spain (Ref. FEM2016-75317-R; Ref. PSI2009- 08472; Ref. FEM2012-35053) and Complutense-Santander Back grant (Ref. CT17/17-CT18/17) to SRM.

Conflicts of interest: None of the authors have any conflict of interest. 


\begin{abstract}
Purpose: Several studies have revealed that homeless people suffering from mental health problems are more vulnerable than homeless without those mental health problems. Nevertheless, there is a lack of evidence describing the real circumstances of homeless women. This paper explores the differences between homeless women at high risk of mental ill-health compared to those who do not present this risk. Method: The sample consisted of a group of 120 homeless women in Madrid (Spain). For this study, we collected data on background information (trajectory of homelessness and stressful life events experienced) and current aspects (living conditions, physical health and social support). The risk of mental ill-health has been measured by the short version of the General Health Questionnaire (GHQ-28). Results: The results showed that homeless women with higher risk of mental ill-health had become homeless at a younger age, had experienced more stressful life events in their lives, had a poorer physical health, felt less happy, had less social support and a greater feeling of loneliness when compared to homeless women who did not present risk of mental ill-health. Conclusions: Improving knowledge about the risk of mental ill-health among homeless women is essential for the design of specific psychological interventions within this population.
\end{abstract}

Keywords: homelessness; homeless women; mental health; GHQ. 


\section{Introduction}

In more economically developed societies, homeless people are on the lowest rung of social exclusion. They not only live in extreme poverty, but also suffer from high levels of family and social disengagement, have great difficulty in achieving social/employment reintegration, and suffer from significant mental and physical health problems (Panadero and Vázquez 2016). A lack of housing is a significant determinant factor in health (Angel and Bittschi 2019). Several studies have reported that homeless people are in poorer physical health than the general population (Lebrun-Harris et al. 2013). This poorer state of health leads directly to an increased risk of mortality, twice as high as the general population (Hwang et al. 2009).

However, the relationship between homelessness and health not only manifests itself in physical health problems, but is also apparent in mental health problems (Chambers et al. 2014). Epidemiological data suggest a much higher prevalence of mental disorders among homeless people than in the general population, and indeed, higher than other economically disadvantaged groups (Lebrun-Harris et al. 2013). Specifically, the data indicate that around a third of homeless people present serious mental illnesses such as schizophrenia, bipolar disorder or serious depression (Sullivan et al. 2000), and this prevalence rises to almost 50\% when disorders related to anxious-depressive symptomatology are taken into account (Feeney et al. 2000). Homeless people suffering from mental health problems experience higher rates of unemployment and suicide than other members of the homeless population (Dunne et al. 2012). The data for suicide rates are particularly shocking, as approximately one in three homeless people has attempted suicide at some point in their lives (Vázquez and Panadero 2019).

The study of mental health problems among homeless people is particularly important for understanding the role these problems play in how people become and remain homeless. The study by Nilsson et al. (2019) found that the mental health problems appeared before becoming homeless. However, other studies have also reported that homelessness in turn increases the likelihood of an individual developing mental health problems. Accordingly, prior research (Castellow et al. 2015; Rayburn et al. 2005) point out that the stress and traumatic experiences related to homelessness aggravate symptoms, increase vulnerability and lead to the appearance of other risk factors. In fact, previous studies have found that experiencing Stressful Life Events (SLEs), such as problems of family violence in childhood/adolescence, being abandoned, arrested or detained for a crime, among others (List of stressful life events for people in social exclusion; Panadero et al. 2018), has a direct effect on the chronification of homelessness, or as it has been reported, it's the 'revolving door to homelessness' (Roca et al. 2019).

Mental health problems have also been linked to the duration and number of episodes of homelessness. Lippert and Lee (2015), found a higher prevalence of mental health problems with chronic and episodic events, compared to those who had just become homeless. As a general rule, the time a person has spent homeless its directly correlated to suffering from anxiety, depression and adaptive disorders (Nino et al. 2009). Furthermore, the prevalence of comorbid disorders among homeless people is $39 \%$ in those with three or more episodes of homelessness, and 35\% among those who have been living homeless for more than a year (National Alliance to End Homelessness 2007). However, the data obtained by Panadero-Herrero and Muñoz-López (2014) contradict the above findings, as they showed that the people who had spent less than one year time homeless had worse scores for anxiety, insomnia and social dysfunction than people in the same situation for more than five years. 
Another crucial variable for understanding the relationship between mental health and homelessness is the role played by social support networks. Homelessness is characterized by high levels of loneliness and major difficulties with establishing adequate social support networks (Bower 2018; Kidd and Shahar 2008). The research carried out by Hwang et al. (2009) found that social support was associated with lower rates of mental health problems, lower levels of suicidal ideation, and lower levels of substance abuse.

Although the situation of homeless women has been studied at much less extent, the data suggest that these women present some significant vulnerability factors, such as SLEs, mental health problems, risk behaviors and lifestyles (Bonugli et al. 2013; Duke and Searby 2019). Previous studies have shown that women in a situation of major social exclusion have special needs that are different from those of their male counterparts, they suffer from more acute processes of victimization, and they present idiosyncratic mental health problems (Tsai et al. 2015). The difficulties resulting from the interaction between socioeconomic level and mental health problems appear to be more outstanding among pregnant women (van Heyningen et al. 2017) and homeless women (Greenberg and Rosenheck 2010). Accordingly, Riley et al. (2014) found that $97 \%$ of homeless women had at least one psychiatric disorder: $85 \%$ met the criteria for substance abuse disorder, $70 \%$ presented mood disorders, and $74 \%$ had anxiety disorders.

We therefore aim with this study to examine the differences between homeless women with a high risk of mental ill-health (HW-MI) and homeless women who do not have this risk with regards to various associated variables: sociodemographic characteristics, living conditions, SLEs, health, well-being and social support. The main hypothesis was that HW-MI would show worse living conditions, a greater chronicity of the homeless situation, more SLEs, more co-morbidity with other health conditions, lower well-being levels and worse social support networks than homeless women who are not at risk. The results of this study ultimately seek to assess the situation of homeless women in depth and identify factors related to mental health problems.

\section{Method}

\section{Participants}

The study was carried out on a sample of 138 homeless women in Madrid (Spain). After removing 18 participants with missing data in the short version of the General Health Questionnaire - GHQ-28, data analysis was conducted in the remaining a sample of 120 women. The data were collected during January 2014 - January 2018. A strict definition was used for homeless women: a woman who had spent the night before being contacted by the interviewer in a shelter for the homeless, on the street or other places not initially designed for sleeping (cars, underground railway stations, abandoned buildings, etc.) (Toro 1998). Inclusion criteria were: participants were 18 years old or above (i.e., of legal age in Spain). Exclusion criteria were: 1) not being able to understand the interview questions in Spanish or English; and 2) to show any serious cognitive impairments or alcohol/drug effects during the interview.

\section{Procedure}

In this cross-sectional study, the homeless women were contacted on the street, in shelters or in other facilities that provide care for this group, by a group of interviewers which had been previously trained to conduct structured interview and in dealing with people in situations of social exclusion. After the objectives of the research were 
explained to the participants, they were asked to sign an informed consent. The interviews were conducted voluntarily and anonymously, and the duration ranged between 45 and 80 minutes. All procedures were approved by the University Ethics Committee of Complutense of Madrid (Ref. 2017/18-004) and followed the 1964 Helsinki declaration for outstanding ethical standards.

In this study, the short version of the General Health Questionnaire was used (GHQ-28; Goldberg and Hillier 1979); specifically, the validated Spanish adaptation done by Lobo, Pérez-Echeverría, \& Artal (1986). This questionnaire comprises four subscales that measure somatic symptoms, anxiety and insomnia, social dysfunction, and depression. The scores went from 0-100 with higher scores meaning better health status. The General Health Questionnaire (GHQ; Goldberg 1972) is a widely used self-report measure for assessing psychiatric morbidity (Rocha et al. 2011). The most restrictive cutoff point $(\mathrm{CP}=6 / 7)$ was used to dichotomize the total GHQ-28 score, dividing the sample of homeless women into two subgroups: of the 120 homeless women who participated in this study, $58 \%(n=70)$ were at high risk of mental ill-health (GHQ-28 $\geq 7)$ while the remaining $42 \%(n=50)$ did not present this risk (GHQ-28<7). This cut-off point has shown adequate psychometric properties in the Spanish validation, with a correct identification percentage in $85 \%$ of cases, a sensitivity of over $70 \%$, and a specificity between 85 and 90\% (Lobo et al. 1986; Muñoz et al. 1995).

\section{Statistical analysis}

Chi-Square for categorical variables and Student $t$ for continuous variables were performed to analyze the differences between HW-MI and homeless women without mental ill-health risk. For all the analyses: 1) basic assumptions were tested; and 2) effect sizes were carried out using Cohen $d$ (for continuous variables), Odds Ratio (for dichotomous variables) and Gamma Test (for ordinal variables). SPSS 22 for Windows was used for all analyses, employing G*Power software (v. 3.1) for Cohen $d$ calculation. Analysis were conducted in a per protocol basis.

\section{Results}

The mean age of participants was 45.52 years $(S D=11.38)$, they were mainly from Spain (65.2\%), $60.8 \%$ of them had kids, $61 \%$ were single, and $22.5 \%$ had not completed primary education (i.e., 12 years old). No significant differences were found between the participants who scored higher than 7 on the GHQ-28, than those with lower scores for the main sociodemographic variables: age $\left(t_{(118)}=1.71, p>.05\right)$, nationality $\left(\chi^{2}{ }_{(1)}=.06\right.$, $p>.05)$, or level of education $\left(\chi^{2}{ }_{(3)}=6.51, p>.05\right)$.

Table 1 shows the differences between the two groups for the different variables related to living conditions (housing situation, homelessness, economic situation and work). The results indicated that the odds of sleeping on the street was five times higher among HW-MI $(O R=5.05)$ than in women not at risk. As for homelessness, statistically significant differences were observed for the age at which the women became homeless for the first time. Participants who scored $>7$ on the GHQ-28 had become homeless at earlier ages than the participants who scored below that level, with a medium-large effect size $(d=.51)$. However, no differences between the groups in terms of the time spent homeless or the number of episodes of homelessness, were observed. Finally, for the variables related to working, the HW-MI had worked for significantly fewer months in their lives $(d=.47)$, although no differences between groups were found for the other occupational variables. 
Table 1: Living conditions among homeless women according to the risk of suffering from mental health problems.

Score GHQ-28 Total

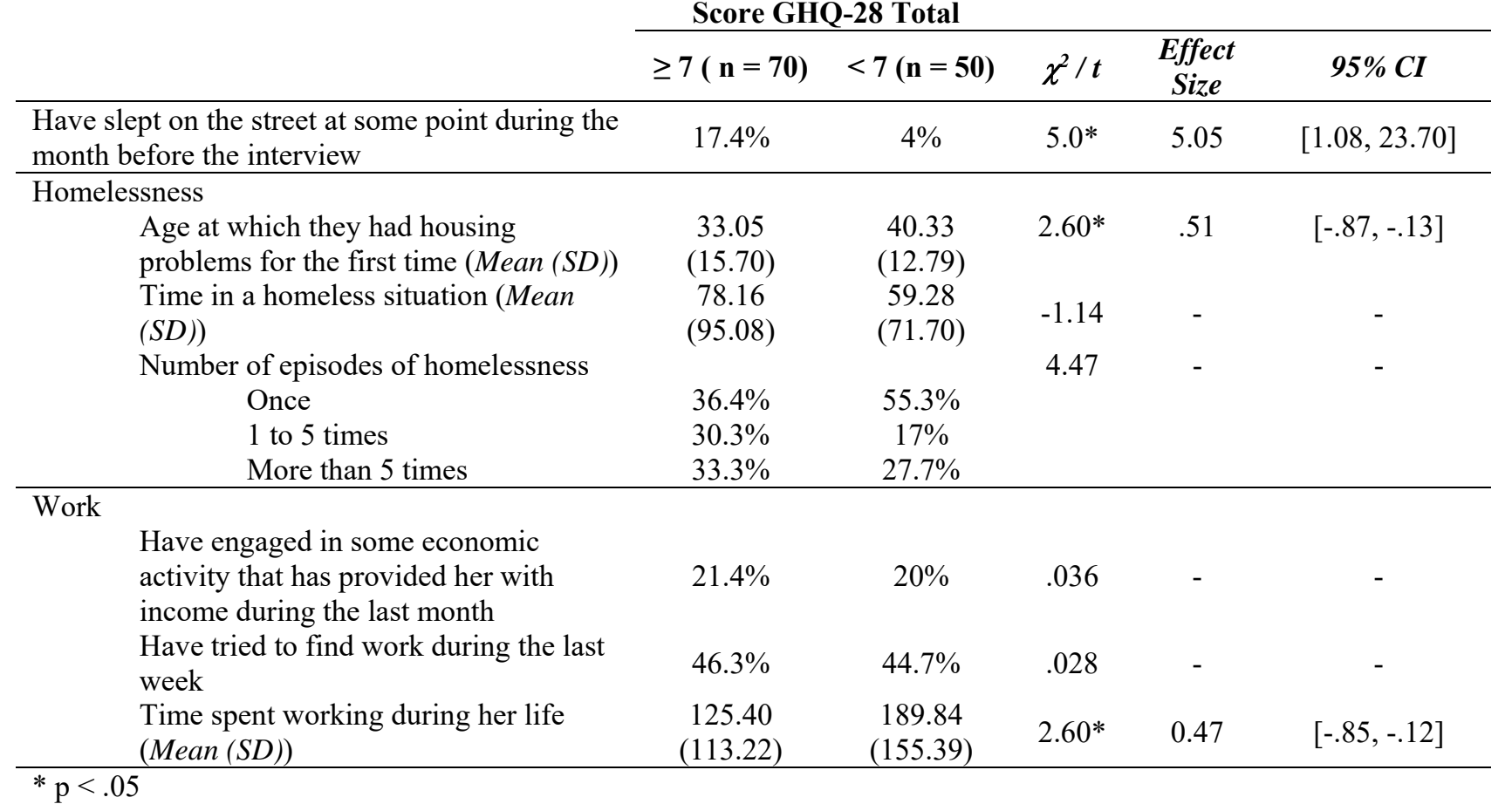

Table 2 presents the data referring to SLEs. The complete list of the SLEs evaluated is attached in the Supplementary Material (Supplementary Table 1 and Table 2 ). For both events, in childhood and adolescence and life-long events, significant differences were observed between groups. The percentage of HW-MI was significantly higher than in the other group. In childhood and adolescence SLEs, the odds of having been abandoned or of having housing problems was almost five times higher among HWMI than among those who presented a lower risk. Furthermore, the odds of having parents with drug abuse problems and of having suffered sexual abuse in their childhood/adolescence was around 4 times higher among HW-MI. Meanwhile, for lifelong SLEs, the data showed that the odds of having experienced economic problems was 8.8 times higher among HW-MI. Those who had suffered from an illness, injury, serious accident or unemployment problems had 4.2 times more probability of presenting a mental health problem compared to those without risk. Finally, the odds of having attempted suicide throughout their life was 3.6 times greater among the participants with scores higher than 7 in the GHQ-28. 
Table 2: Stressful life events among homeless women according to the risk of suffering from mental health problems.

Score GHQ-28 Total

$\geq 7(\mathrm{n}=70) \quad<7(\mathrm{n}=50) \quad \chi^{2} \quad$ OR $\quad 95 \% C I$

\begin{tabular}{llllll}
\hline Childhood and adolescence (before 18 Years Old) & & & & & \\
A parent had problems with drugs & $15.7 \%$ & $4.1 \%$ & $4.01^{*}$ & 4.38 & {$[.93,20.74]$} \\
Serious fights and arguments between the parents & $42.9 \%$ & $24.5 \%$ & $4.26^{*}$ & 2.31 & {$[1.03,5.17]$} \\
Be abandoned & $17.4 \%$ & $4.1 \%$ & $4.85^{*}$ & 4.95 & {$[1.05,23.22]$} \\
Housing problems in childhood & $17.4 \%$ & $4.1 \%$ & $4.85^{*}$ & 4.95 & {$[1.05,23.22]$} \\
Suffered from sexual abuse & $39.1 \%$ & $14.3 \%$ & $8.62^{*}$ & 3.86 & {$[1.51,9.82]$} \\
\hline Throughout life & & & & & \\
Suffered from a serious illness, injury or accident & $65.2 \%$ & $30.6 \%$ & $13.73^{* *}$ & 4.25 & {$[1.94,9.30]$} \\
Suffered from serious unemployment problems & $91.3 \%$ & $71.4 \%$ & $8.04^{*}$ & 4.20 & {$[1.48,11.90]$} \\
Suffered from major financial problems & $95.7 \%$ & $71.4 \%$ & $13.63^{* *}$ & 8.80 & {$[2.37,32.70]$} \\
Drunk too much at some point in her life & $46.4 \%$ & $20.4 \%$ & $8.43^{*}$ & 3.37 & {$[1.46,7.82]$} \\
Abused drugs at some point in her life & $44.9 \%$ & $22.4 \%$ & $6.32^{*}$ & 2.82 & {$[1.24,6.41]$} \\
Done work that separated her from her home & $47.8 \%$ & $28.6 \%$ & $4.43 *$ & 2.29 & {$[1.05,5.00]$} \\
Suffered from sexual assault (over 18 years old) & $41.2 \%$ & $22.4 \%$ & $4.50^{*}$ & 2.42 & {$[1.06,5.53]$} \\
Had Attempted Suicide & $59.4 \%$ & $28.6 \%$ & $10.96^{* *}$ & 3.66 & {$[1.67,8.02]$} \\
Has been reported to the police & $43.5 \%$ & $22.4 \%$ & $5.59^{*}$ & 2.66 & {$[1.17,6.05]$} \\
Suffered from a miscarriage & $31.9 \%$ & $14.6 \%$ & $4.55^{*}$ & 2.74 & {$[1.06,7.08]$} \\
Separation from a child (adoption, abandoned) & $40.6 \%$ & $22.4 \%$ & $4.26^{*}$ & 2.36 & {$[1.03,5.39]$} \\
\hline
\end{tabular}

$* \mathrm{p}<.05 ; * * \mathrm{p}<.001$

Table 3 shows the results of the comparison for various health-related incidences between homeless women with scores higher or lower than 7 in the GHQ-28. Homeless women with possible mental health problems perceived their health as "bad" or "very bad" to a greater extent (with a medium effect size; Gamma $=.50$ ). Furthermore, this data was accentuated when the participants are asked to rate their current state of health using a visual analogue scale (a "feeling thermometer" scale, on which the woman is asked to rate their health from 0 to 100 ; with 100 being the best health that the person can imagine and 0 the worst health), which showed significant differences between groups with a very large effect size $(d=.99)$. The odds of suffering from a serious or chronic disease was 2.5 times higher among HW-MI, while the odds of having suffered from pain or physical discomfort was 4.4 times higher. However, no differences were observed in terms of the number of homeless women suffering from a disability. 
Table 3: Health status among homeless women according to the risk of suffering from mental health problems.

Score GHQ-28 Total

\begin{tabular}{|c|c|c|c|c|c|}
\hline & \\
\hline & $\geq 7(n=70)$ & $<7(\mathrm{n}=50)$ & $\chi^{2 / t}(\mathrm{gl})$ & Effect Size & $95 \% C I$ \\
\hline Perceived health & & & $14.46^{*}$ & 0.50 & {$[.39, .61]$} \\
\hline Very good & $8.6 \%$ & $26 \%$ & & & \\
\hline Good & $22.9 \%$ & $34 \%$ & & & \\
\hline Fair & $32.9 \%$ & $28 \%$ & & & \\
\hline Poor & $20 \%$ & $10 \%$ & & & \\
\hline Very bad & $15.7 \%$ & $2 \%$ & & & \\
\hline $\begin{array}{l}\text { A doctor has told her that you have a } \\
\text { serious or chronic illness }\end{array}$ & $61.4 \%$ & $38 \%$ & $6.41^{*}$ & 2.60 & {$[1.23,5.48]$} \\
\hline $\begin{array}{l}\text { Have suffered from some sort of pain or } \\
\text { physical discomfort (last month) }\end{array}$ & $81.4 \%$ & $50 \%$ & $13.31 * *$ & 4.39 & {$[1.93,9.94]$} \\
\hline Have a disability & $41.4 \%$ & $34 \%$ & 0.68 & - & - \\
\hline State of health today $(0-100)$ (Mean $(S D))$ & $50.71(26.75)$ & $74.50(20.51)$ & $5.28 * *$ & .99 & {$[-1.35,-.59]$} \\
\hline
\end{tabular}

$* \mathrm{p}<.05 ; * * \mathrm{p}<.001$

The differences between homeless women with higher and lower risks of suffering mental health problems in their perceived levels of happiness provided another interesting piece of data (Table 4). The results indicated that participants scoring higher than 7 in the GHQ-28 perceived themselves as significantly unhappier than the comparison group, with a large effect size $(d=-.58)$. In addition, HW-MI felt significantly lonelier than homeless women without this risk $(d=.56)$, and they had significantly fewer people to talk to when they are sad, overwhelmed or upset $(O R=.24)$.

Table 4: Well-being and social support among homeless women according to the risk of suffering from mental health problems.

Score GHQ-28 Total

\begin{tabular}{|c|c|c|c|c|c|}
\hline & \\
\hline & $\geq 7(n=70)$ & $<7(n=50)$ & $x^{2}$ & Effect Size & $95 \% \mathrm{CI}$ \\
\hline Perceived overall happiness & & & $23.95^{* *}$ & -.58 & {$[-.50,-.68]$} \\
\hline Very unhappy & $15.9 \%$ & $2 \%$ & & & \\
\hline Quite unhappy & $14.5 \%$ & $0 \%$ & & & \\
\hline A little unhappy & $14.5 \%$ & $6 \%$ & & & \\
\hline Neither happy nor unhappy & $21.7 \%$ & $24 \%$ & & & \\
\hline A little happy & $21.7 \%$ & $32 \%$ & & & \\
\hline Quite happy & $5.8 \%$ & $16 \%$ & & & \\
\hline Very happy & $5.8 \%$ & $20 \%$ & & & \\
\hline Feeling lonely or abandoned & & & $19.15^{* *}$ & .56 & {$[.45-.69]$} \\
\hline Not at all & $19.4 \%$ & $50 \%$ & & & \\
\hline Not much & $14.9 \%$ & $25 \%$ & & & \\
\hline Quite a lot & $25.4 \%$ & $10.4 \%$ & & & \\
\hline A lot & $40.3 \%$ & $14.6 \%$ & & & \\
\hline $\begin{array}{l}\text { Do you have someone to talk to when } \\
\text { you feel sad, overwhelmed or upset? }\end{array}$ & $63.8 \%$ & $88 \%$ & $8.84^{*}$ & .24 & {$[.09-.64]$} \\
\hline
\end{tabular}

$* \mathrm{p}<.05 ; * * \mathrm{p}<.001$ 


\section{Discussion and Conclusions}

Mental health is a key variable for understanding the etiology and maintenance of homelessness, particularly in the case of homeless women. The current study has demonstrated that women with a high risk of mental ill-health have poorer living conditions, are more vulnerable, are at a higher risk of sleeping on the street and are in poorer physical and mental health status. This is consistent with the results of other international studies, which have highlighted a more marked deterioration in mental health among women who literally sleep on the street (Nyamathi et al. 2000). In the case of Spain, available data also suggest that homeless women have a high prevalence of mental health problems, and even higher than other European countries (Moss 2018).

Differences were also observed in these women's trajectory of homelessness. Concretely, HW-MI had become homeless at an earlier age. However, no significant differences were observed for the duration of homelessness between groups. The studies carried out to date have found contradictory results. Some studies have found that the time a person has been living homeless correlates positively with the presence of a mental health problem (Nino et al. 2009). However, other studies have found precisely the opposite: people who have spent less time living homeless have worse scores for anxiety, insomnia and social dysfunction (Panadero-Herrero and Muñoz-López 2014). As for the number of episodes of homelessness that the women have experienced, a study carried out by Lippert and Lee (2015) observed that the number of these episodes affects their mental health, but these differences between the two groups were not observed in this study.

In other words, mental health appears to be related to the age when the person became homeless, but not to the time spent homeless or the number of episodes of homelessness. This result could be interpreted in various ways: on one hand, it could be due to a ceiling effect, i.e. the rates of chronicity among homeless women in Spain are generally so high that mental health is not significant to make a distinction among groups; however, it could also be due to the fact that HW-MI have access to specific resources for this group (e.g. employment programmes for people with mental health problems), which could reduce its long-term chronification (despite their situation being more serious at the beginning of their homelessness). Finally, although no differences were found between the groups with regards to engagement in economic activities during the previous month or attempts to obtain employment, the results showed that women at risk of suffering from mental health problems had worked less during their lifetime. This result is consistent with Dunne et al. (2012). This finding is crucial for designing social policies focusing on employment reintegration by means of jobs adapted to this population.

The large number of SLEs that homeless women have experienced both in childhood/adolescence and throughout their lives is particularly important. As observed in previous studies (Chambers et al. 2014), the number of SLEs increases among HWMI. This result could be an important aspect for understanding how people in this subgroup become and remain homeless, as well as their increased vulnerability. These

factors must be taken into account when designing specific interventions that are sensitive to the processes of victimization that these women have experienced (Patel et al. 2019).

Physical health problems have been an extensively studied issue related to homeless people, and have been highlighted as a risk factor for homeless women (Johnson et al. 2017). The overall examination of physical and mental health problems in this study 
showed that the perceived health of HW-MI was much worse for all the outcomes assessed: they considered themselves to be in poorer health, and suffer from chronic diseases and pain to a greater extent. However, no significant differences were found between the groups in terms of suffering from/reporting a disability. As for outcomes of well-being, the research carried out by Sun et al. (2012) found lower rates of subjective well-being in homeless people. Likewise, the results of this study showed that HW-MI were unhappier than those with a lower risk.

Finally, our results also suggested that the rates of loneliness and the lack of social support were higher for women who are more likely to suffer from mental health problems, replicating previous studies that have highlighted the high levels of loneliness experienced by homeless people and their difficulties in establishing social relationships (Bower 2018; Kidd and Shahar 2008). Phipps et al. (2019) highlighted the role that the social support and life satisfaction play in maintaining and exiting homelessness. The need to increase the quantity and quality of social relationships appears to be a key factor in reducing the feeling of loneliness, and this in turn would have a positive impact on the mental health of these women.

This study has a number of limitations. The results discussed are based on a crosssectional study of women that were not formally diagnosed with a mental illness, and as such it is impossible to determine their causality. Future studies should include longitudinal information to determine whether mental health problems are the reason for other risk factors, or whether on the contrary, the accumulation of other vulnerability factors lead to an increased risk of developing mental health problems among homeless people (Guillén et al. 2020) Furthermore, this research has no comparison group of women who are not homeless or of homeless men, which would help to determine whether the relations observed are due to the individual concerned being homeless, being a woman or an interaction of both. It is important to take into account that these results come from urban areas in Spain, and future studies should analyze the replicability of these findings in other contexts (e.g., rural areas and other countries), as well as the transcultural differences in such processes.

Summarizing, the data obtained suggest that mental health problems are a fundamental variable in homeless women, both because of its high level of prevalence and because of its relationship with other vulnerability factors. Programmes and interventions aimed at this population generally have a primarily social focus. However, these results highlight the importance of including empirically validated psychological interventions aimed at treating mental health problems and other associated factors. Costeffective psychological interventions would possibly reduce the unnecessary public expenditure arising from the secondary consequences of the lack of psychological treatments.

Ethical standards: All procedures were approved by the University Ethics Committee of Complutense of Madrid (Ref. 2017/18-004) and followed the 1964 Helsinki declaration.

Informed consent: Informed consent was obtained from all individual participants included in the study. 


\section{References}

Angel S, Bittschi B (2019) Housing and health. Rev Income Wealth 65:495-513. https://doi.org/10.1111/roiw.12341

Bonugli R, Lesser J, Escandon S (2013) "The second thing to hell is living under that bridge": narratives of women living with victimization, serious mental illness, and in homelessness. Issues Ment Health Nurs 34:827-835. https://doi.org/10.3109/01612840.2013.831149

Bower M (2018) Homelessness, loneliness and intersectionality: an Australian study

Castellow J, Kloos B, Townley G (2015) Previous homelessness as a risk factor for recovery from serious mental illnesses. Community Ment Health J 51:674-684. https://doi.org/10.1007/s10597-014-9805-9

Chambers C, Chiu S, Scott AN, et al (2014) Factors associated with poor mental health status among homeless women with and without dependent children. Community Ment Health J 50:553-559. https://doi.org/10.1007/s10597-013-9605-7

Craig T, Hodson S (1998) Homeless youth in London: I. Childhood antecedents and psychiatric disorder. Psychol Med 28:1379-1388

Duke A, Searby A (2019) Mental ill health in homeless women: a review. Issues Ment Health Nurs 40:605-612. https://doi.org/10.1080/01612840.2019.1565875

Dunne E, Duggan M, O'Mahony J (2012) Mental health services for homeless: patient profile and factors associated with suicide and homicide. Ir Med J 105 (3):71-74

Feeney A, McGee H, Holohan T, Shannon H (2000) The health of Hostel-dwelling men in Dublin: perceived health status, lifestyle and healthcare utilisation of homeless men in south inner city Dublin hostels. Department of General Practice \& Health Services Research Centre, Department of Psychology, RCSI \& Department of Public Health, Eastern Health Board.

Goldberg DP (1972) The detection of psychiatric illness by questionnaire. Oxford University Press: London

Goldberg DP, Hillier VF (1979) A scaled version of the General Health Questionnaire. Psychol Med 9:139. https://doi.org/10.1017/S0033291700021644

Greenberg GA, Rosenheck RA (2010) Mental health correlates of past homelessness in the national comorbidity study replication. J Health Care Poor Underserved 21:1234-1249. https://doi.org/10.1353/hpu.2010.0926

Guillén AI, Marín C, Panadero S, Vázquez JJ (2020) Substance use, stressful life events and mental health: a longitudinal study among homeless women in Madrid (Spain). Addict Behav 103:106246. https://doi.org/10.1016/j.addbeh.2019.106246

Hwang SW, Wilkins R, Tjepkema M, et al (2009) Mortality among residents of shelters, rooming houses, and hotels in Canada: 11 year follow-up study. BMJ 339:b4036. https://doi.org/10.1136/bmj.b4036

Johnson G, Ribar D, Zhu A (2017) Women's homelessness: international evidence on causes, consequences, coping and policies. SSRN Electron J. https://doi.org/10.2139/ssrn.2927811

Kidd S, Shahar G (2008) Resilience in homeless youth: the key role of self-esteem. Am J Orthopsychiatry 78:163-172. https://doi.org/10.1037/0002-9432.78.2.163

Lebrun-Harris LA, Baggett TP, Jenkins DM, et al (2013) Health status and health care experiences among homeless patients in federally supported health centers: findings from the 2009 patient survey. Health Serv Res 48:992-1017. https://doi.org/10.1111/1475-6773.12009

Lippert AM, Lee BA (2015) Stress, coping, and mental health differences among homeless people. Sociol Inq 85:343-374. https://doi.org/10.1111/soin.12080

Lobo A, Pérez-Echeverría M, Artal J (1986) Validity of the scaled version of the General 
Health Questionnaire (GHQ-28) in a Spanish population. Psychol Med 16(1):135140

Moss K (2018) A study of women rough sleepers in four European countries. Social Lawyer 7. https://doi.org/10.13169/socialistlawyer.78.0007

Muñoz M, Vázquez C, Cruzado JA (1995) Homeless people in Madrid. Psychosoc. Epidemiol. Rep.

National Alliance to End Homelessness (2007) Vital mission: ending homelessness among veterans. Washington, DC: National Alliance to End Homelessness

Nilsson SF, Nordentoft M, Hjorthøj C (2019) Individual-level predictors for becoming homeless and exiting homelessness: a systematic review and meta-analysis. J Urban Heal 96:741-750. https://doi.org/10.1007/s11524-019-00377-x

Nino MD, Loya MA, Cuevas MC (2009) Who are the chronically homeless? Social characteristics and risk factors associated with chronic homelessness. J Soc Distress Homeless 19:41-65. https://doi.org/10.1179/105307809805365145

Nyamathi AM, Leake B, Gelberg L (2000) Sheltered versus nonsheltered homeless women. J Gen Intern Med 15:565-572. https://doi.org/10.1046/j.15251497.2000.07007.x

Panadero-Herrero S, Muñoz-López M (2014) Health, quality of life and consumption of substances as a function of time in a homeless situation. Ann Psychol 30(1):70-77

Panadero S, Martín R, Vázquez JJ (2018) Suicide attempts and stressful life events among homeless people in Madrid (Spain). J Community Appl Soc Psychol 28:200-212. https://doi.org/10.1002/casp.2351

Panadero S, Vázquez JJ (2016) At the frontiers of citizenship. Situation of the homeless and at risk of social exclusion in Madrid. Universidad de Alcalá (UAH)

Patel AR, Weobong B, Patel VH, Singla DR (2019) Psychological treatments for depression among women experiencing intimate partner violence: findings from a randomized controlled trial for behavioral activation in Goa, India. Arch Womens Ment Health 22:779-789. https://doi.org/10.1007/s00737-019-00992-2

Phipps M, Dalton L, Maxwell H, Cleary M (2019) Women and homelessness, a complex multidimensional issue: findings from a scoping review. J Soc Distress Homeless 28:1-13. https://doi.org/10.1080/10530789.2018.1534427

Rayburn N, Wenzel S, Elliot M, et al (2005) Trauma, depression, coping, and mental health service seeking among impoverished women. J Consult Clin Psychol 73:667

Riley ED, Cohen J, Knight KR, et al (2014) Recent violence in a community-based sample of homeless and unstably housed women with high levels of psychiatric comorbidity. Am J Public Health 104:1657-63. https://doi.org/10.2105/AJPH.2014.301958

Roca P, Panadero S, Rodríguez-Moreno S, et al (2019) The revolving door to homelessness. The influence of health, alcohol consumption and stressful life events on the number of episodes of homelessness. Ann Psychol 35:175-180. https://doi.org/10.6018/ANALESPS.35.2.297741

Rocha K, Pérez K, Rodríguez-Sanz M, Obiols JE (2011) Psychometric properties and normative values of the General Health Questionnaire (GHQ-12) in the general Spanish population. J Clin Heal Psychol 11:125-139

Sullivan G, Burnam A, Koegel P, Hollenberg J (2000) Quality of life of homeless persons with mental illness: results from the course-of-homelessness study. Psychiatr Serv 51:1135-1141. https://doi.org/10.1176/appi.ps.51.9.1135

Sun S, Irestig R, Burström B, et al (2012) Health-related quality of life (EQ-5D) among homeless persons compared to a general population sample in Stockholm County, 2006. Scand J Public Health 40:115-125. 
https://doi.org/10.1177/1403494811435493

Toro P (1998) Homeless, en S. Bellock y M. Hersen (Eds). Comprehensive Clinical Psychology. Elservier Science.

Tsai AC, Weiser SD, Dilworth SE, et al (2015) Violent victimization, mental health, and service utilization outcomes in a cohort of homeless and unstably housed women living with or at risk of becoming infected with HIV. Am J Epidemiol 181:817-826. https://doi.org/10.1093/aje/kwu350

van Heyningen T, Honikman S, Myer L, et al (2017) Prevalence and predictors of anxiety disorders amongst low-income pregnant women in urban South Africa: a crosssectional study. Arch Womens Ment Health 20:765-775. https://doi.org/10.1007/s00737-017-0768-z

Vázquez JJ, Panadero S (2019) Suicidal attempts and stressful life events among women in a homeless situation in Madrid (Spain). Am J Orthopsychiatry 89:304-311. https://doi.org/10.1037/ort0000387 